\title{
El examen físico tiene poca precisión para la detección de las presentaciones no-cefálicas
}

\section{Objetivo}

Evaluar la precisión diagnóstica del examen clínico para determinar la presentación fetal en embarazos de término.

\section{Diseño}

Estudio analítico de corte transversal. El método a evaluar fue el examen físico y el test de referencia, la ecografía obstétrica.

\section{Lugar}

Clínica prenatal en un hospital terciario de Sydney, Australia.

\section{Pacientes}

Fueron evaluadas 1633 mujeres con embarazos únicos con edades gestacionales entre 35 y 37 semanas que habían asistido a la consulta prenatal.

\section{Descripción de las pruebas y de la prueba de referencia}

La presentación fetal fue evaluada durante la consulta prenatal a través del examen clínico, realizándose luego una ecografía obstétrica para la confirmación del diagnóstico clínico. Los clínicos y los ecografistas conocían que se estaba realizando este estudio pero estaban ciegos a los resultados.

\section{Medición de Resultados Principales}

Sensibilidad, especificidad, valor predictivo positivo y negativo comparando la evaluación clínica con la ecografía. Se calcularon además estos indicadores según determinadas características maternas.

\section{Resultados Principales}

La ecografía identificó $130(8 \%)$ presentaciones no-cefálicas, de las cuales $103(6,3 \%)$ fueron podálicas y $27(1,7 \%)$ transversas u oblicuas. La sensibilidad del examen clínico para detectar las presentaciones no-cefálicas fue 70\% (IC95\%: 62\%-78\%) y la especificidad 95\% (IC95\%: 94-96\%). El valor predictivo negativo de la prueba fue $55 \%$ y el positivo $97 \%$. La sensibilidad del examen clínico para detectar las presentaciones no-cefálicas no se asoció con ninguna de las características maternas estudiadas aunque hubo una tendencia a mejorar la sensibilidad en mujeres multíparas y en aquellas con bajo índice pondo-estatural. La proporción de mujeres en quienes se diagnosticó correctamente por el examen físico la presentación cefálica fue superior en mujeres con mayores edades gestacionales y con menores índices pondo-estaturales.

\section{Conclusiones}

El examen clínico no fue lo suficientemente sensible como para detectar la presentación no-cefálica y permitir un manejo apropiado de esta complicación obstétrica.

Fuente de financiamiento: Australian National Health and Medical Research Council (NHMRC).

\section{Comentario}

Este artículo muestra en forma simple una evaluación de la precisión de un diagnóstico que el clínico obstetra y la partera realizan cotidianamente, como es el diagnóstico de la presentación fetal. Una correcta y oportuna apreciación de la presentación fetal tiene implicancias importantes. Por un lado permitirá hacer una versión externa y si la misma es exitosa disminuirá las consecuencias de un parto en presentación no-cefálica. La revisión sistemática de la literatura ha mostrado que la versión externa a término es una maniobra sencilla e inocua y que consigue una reducción significativa de los partos no-cefálicos y la cesárea'. Por el contrario, el diagnóstico tardío de la presentación no-cefálica -ya durante el trabajo de parto- se asocia con una mayor morbi-mortalidad materna e infantil $\left.\right|^{2}$.

Hasta la fecha no disponíamos de un estudio de buen diseño que permitiera valorar en forma confiable la utilidad de la evaluación clínica obstétrica para el diagnóstico de la presentación fetal. Este estudio evalúa esta maniobra utilizada comúnmente en nuestro medio. Sólo el $70 \%$ de las presentaciones no-cefálicas fueron diagnosticadas. La aplicación de estos hallazgos significa que en una población de 1000 mujeres, el examen clínico diría que 101 de ellas tendrían presentación no-cefálica pero sólo en 56 de ellas el diag- nóstico sería correcto y 24 mujeres con presentación no-cefálica serían ignoradas. El estudio no analizó si la eficacia diagnóstica estaba relacionada con alguna característica del operador que hizo las maniobras, como especialización, años de experiencia u otras. La aplicación de la ecografía a todas las mujeres embarazadas a término para un mejor diagnóstico de la presentación resulta oneroso y sería de interés hacer estudios de costo efectividad ${ }^{2} 0$ costo utilidad ${ }^{2}$ de esta conducta. Por otro lado, resulta importante mejorar el diagnóstico clínico de la presentación fetal desarrollando métodos de enseñanza, de control y retroalimentación para mejorar su eficiencia.

\section{Conclusiones del comentador}

Resulta de mucho interés ver que el diagnóstico clínico de la presentación fetal en el embarazo a término tiene una baja precisión. Es importante desarrollar metodologías que evalúen su sensibilidad y especificidad en nuestro medio y para que, de acuerdo a ello, establecer intervenciones tendientes a mejorar la eficiencia del método clínico.

José Belizán [Instituto de Efectividad Clínica y Sanitaria. ]

Recibido el 20/11/06 y aceptado el 11/12/06.

Belizán J. Evid. actual. páct. ambul. 9(6);173. Nov-Dic. 2006. La evaluación clínica es de poca utilidad para la detección y el manejo obstétrico de las presentaciones no-cefálicas. Nassar N, Roberts CL, Cameron CA, Olive EC. Diagnostic accuracy of clinical examination for detection of non-cephalic presentation in late pregnancy: cross sectional analytic study. BMJ 2006;333:578-80. PMID: 1689132

\section{Referencias}

1. Hofmeyr GJ, Kulier R. External cephalic version for breech presentation at term. The Cochrane Database of Systematic Reviews 1996, Issue 1. Art. No.: CD000083. DOI: 10.1002/14651858.CD000083

2. Waterstone M, Bewley S, Wolfe C. Incidence and predictors of severe obstetric morbidity: case-control study. BMJ 2001; 322:1089-93. 